\title{
I Seminário sobre Revistas de Cultura e Extensão: breve relato
}

\author{
$1^{\text {st }}$ Colloquium on Culture and Extension Magazines: \\ a brief report
}

Em setembro, no dia 21, como parte do programa do Seminário Nacional de Cultura, aconteceu o I Seminário sobre Revistas de Cultura e Extensão. Esse seminário teve como finalidade discutir os objetivos de publicações da área.

$\mathrm{Na}$ abertura, a professora doutora Diana Helena de Benedetto Pozzi, coordenadora da mesa de debates, propôs a ideia de que uma revista já é uma atividade de Extensão e, sendo da área de Cultura e Extensão, deve atuar sobre a cultura de uma sociedade. Os professores doutores João Frederico da Costa Azevedo Meyer, Pró-Reitor de Extensão e Assuntos Comunitários da Unicamp, e Maria Cândida Soares Del Masso, assessora da Pró-Reitoria de Extensão da Unesp, apresentaram levantamentos sobre o que existe de publicações na área de Cultura e Extensão no Brasil e ficou clara a predominância de revistas que atendem àqueles trabalhos que não foram aceitos nos periódicos de suas áreas específicas.

A apresentação do professor João Frederico da Costa Azevedo Meyer mostrou a dificuldade em validar as publicações em revistas de Cultura e Extensão para efeitos de currículo, fato também comentado pela professora Maria Cândida. O professor doutor José Nicolau Gregorin Filho, assessor da Pró-Reitoria de Cultura e Extensão Universitária da USP, presente ao seminário, comentou que qualquer publicação em revista de área específica é uma atividade de Extensão e notoriamente, em geral, essa atividade não é considerada como tal e sim como atividade de Pesquisa.

A professora Diana acrescentou que uma revista de Cultura e Extensão, aberta a todas as áreas e à comunidade, deve ter uma linguagem própria e acessível a todos e não atender somente ao jargão de cada área. $\mathrm{O}$ uso de linguagem especializada geraria diminuição do interesse por parte dos leitores, pois cada texto atingiria tão somente o público da área específica.

O professor doutor Plínio Martins Filho, presidente da Edusp, falou sobre a importância da editoração e da apresentação dos periódicos para que se atenda ao objetivo desejado.

Ficou aparente que uma revista específica de Cultura e Extensão, a qual engloba atividades de Ensino e Pesquisa, deve ter uma apresentação e uma linguagem própria para 
ser interessante à comunidade e conquistar seu espaço como atividade acadêmica. Para isso, não pode ser mero repositório de artigos escritos em jargões específicos e que venham a compor a coletânea de revistas de Cultura e Extensão em razão da recusa pelos periódicos de outras áreas. A revista de Extensão deve, portanto, ser uma atividade que atinja à sociedade no seu todo.

O seminário configurou-se, assim, como um importante espaço para o debate acerca de publicações para a área de Cultura e Extensão.

O seminário na integra poderá ser acessado pelo site www.prceu.usp.br/revista.

DiANA helenA De benedetto pozzI professora doutora da Faculdade de Medicina da Universidade de São Paulo e Editora da Revista Cultura e Extensão USP - e-mail: dianahbp@usp.br. 